\title{
Advanced Available-To-Promise for Order Management Stock-out Situation
}

\author{
Uche Okongwu \\ Toulouse Business School \\ 20 Boulevard Lacrosses - BP 7010, 31068 Toulouse Cedex 7 - France \\ u.okongwu@esc-toulouse.fr \\ Matthieu Lauras \\ Université Toulouse, Mines Albi, Industrial Engineering Department \\ Campus Jarlard, Route de Teillet, 81013 Albi Cedex 9 - France \\ matthieu.lauras@enstimac.fr \\ Vérane Humez \\ Université Toulouse, Mines Albi, Industrial Engineering Department \\ Campus Jarlard, Route de Teillet, 81013 Albi Cedex 9 - France \\ verane.humez@enstimac.fr \\ Lionel Dupont \\ Université Toulouse, Mines Albi, Industrial Engineering Department \\ Campus Jarlard, Route de Teillet, 81013 Albi Cedex 9 - France \\ lionel.dupont@enstimac.fr
}

\begin{abstract}
Many authors have highlighted the gap between the supply side and the demand side of the order fulfilment process. Generally, the latter tends primarily to be "agile" by maximising responsiveness and flexibility while the former tends to be "lean" by maximising efficiency. However, the most fundamental trade-offs in supply chain management are between these two properties. This is the "leagile" objective. In stock-out situation, the delivery options that would minimize the customers' dissatisfaction while reconciling the conflicting objectives of the different actors of the supply network must be defined. Today, no particular method seems to allow managing bulk within this leagile ambition. This paper proposes a non-sequential Advanced Available-to-promise model to tackle this question. The model is applied to a numerical example and the results obtained are used to illustrate the most representative delivery strategies.
\end{abstract}

Keywords : Lean, Agility, Advanced Available-To-Promise, Order Fulfilment Process, Supply Chain, Demand Chain.

\section{Introduction}

Changing technical, economic and business environments force organizations to constantly search for new ways of designing their supply chains in order to improve their competitiveness and profitability. Christopher (1992) defined a supply chain as "the network of organisations that are involved, through upstream and downstream linkages, in the different processes and activities that produce value in the form of products and services 
delivered to the ultimate consumer." The downstream linkages constitute the demand chain (DC), which is defined by Hoover et al. (2001) as "the chain of activities that communicate demand from markets to suppliers." From this definition, the supply chain (SC) can be referred to as the upstream linkages, which encompass all the activities involved in fulfilling the demand by supplying products and/ or services to the market. The customer order decoupling point (CODP) can be used as the point of demarcation between the SC and the DC. The CODP is defined by some authors as the point in the goods flow where forecast-driven production and customer-driven production are separated (Giesberts and van den Tang, 1992).

Integration of SC and DC processes entails developing the communication, co-operation and coordination capabilities of the stakeholders. To achieve this, has the Order Management (OM) activity have to be executed properly. Basically, this activity manages the propagation of the demand in the network by the sending of purchase orders to the supplier and by the acceptance of the orders and the assignment of a due date by the supplier (Chang et al., 2003). In practice, available-to-promise (ATP) methods can help decision makers to choose between different alternatives. However, in case of stock-out, these tools are insufficient for decision making in the face of certain variables such as: unknown availability, product substitution, specific operations and contradictory objectives between different functions (for example, maximizing the turnover of the current month by sending backorders separately versus minimizing costs of transportation by delivering the products later and in one batch). This paper suggests an approach that takes all these cases into consideration in the decision-making process. It also looks at the issue of governance, that is, the decision-making body.

Firstly, the problem of SC's and DC's integration is discussed and our problem statements are presented. Secondly, a literature review of the main tools used to support the Order Management Process is developed. Thirdly, our Advanced ATP model is described and implemented on a case study. Finally, some conclusions and perspectives are discussed.

\section{Supply and Demand Chain Integration}

Ideally, all businesses should aim to manage both the DC and the SC such as to: 1) maximise the satisfaction of the ultimate customer by delivering quickly and responsively error-free products at a relatively low price, and 2) minimise operational cost by eliminating non value-added activities and reducing lead times, thereby creating value for stakeholders. Though there are different definitions of demand chain management (DCM) and supply chain management (SCM) in the literature, some authors argue that SCM is termed DCM to reflect the fact that the chain (or network) is driven by the market, and not by suppliers (Rainbird, 2004). Walters (2006) argues that SCM lays emphasis on efficiency (which consists of minimising operational cost) while DCM lays emphasis on effectiveness (which consists of maximising flexibility and responsiveness), but tries more to reconcile both efficiency and effectiveness. In other words, SCs tend to be "lean" (efficient) by eliminating wastes while DCs tend to be "agile" (flexible and responsive) by providing speedy response to market changes.

It follows that one of the most fundamental trade-offs in SCM (or in DCM) is between efficiency and flexibility/responsiveness. It calls for a "leagile" system. Naylor et al. (1999) defined leagile as: "the combination of the lean and agile paradigms within a total supply chain strategy by positioning the CODP so as to best suit the need for responding to a volatile demand downstream yet providing level scheduling upstream from the decoupling point."

Johansson et al. (1993) had earlier developed a model that would help to understand and manage the leagility concept. Their model, taken further by other authors (Christopher and Towill, 2000; Childerhouse and Towill, 2000), expresses the value delivery of a business in terms of an equation which encompasses market qualifiers and market winners, as follows:

Total value $=\frac{\text { Quality } \times \text { Service }}{\text { Cost } \times \text { LeadTime }}$

In this equation, quality and lead time are market qualifiers for both lean and agile systems. Leagility 
can therefore be achieved by searching for a tradeoff between service level (which is a market qualifier for a lean system and a market winner for an agile system) and cost (which is a market winner for a lean system and a market qualifier for an agile system). Our first problem statement (PS) is therefore:

PS1: How should the demand chain and the supply chain be integrated and managed in order to obtain a leagile system, capable of maximising customer satisfaction?

Walters and Rainbird (2004) argue that a firm is best placed to create value and exploit market opportunities when there is an effective combination of SC capabilities (efficiency) and DC effectiveness to maximise the organisation's overall value chain. This is the role of the order management $(\mathrm{OM})$ activity, which is one of the key components of the order fulfilment process (OFP). An OFP involves generating, filling, delivering and servicing customer orders (Croxton, 2003). The OFP is complex because it is composed of several activities, executed by different functional entities, and heavily interdependent among the tasks, resources and entity involved in the process (Lin and Shaw, 1998). It is difficult to manage because each entity, which intervenes in the process, has its own objectives. In line with our first problem statement, Croxton et al. (2001) note that effective OFP requires integration of the firm's manufacturing, logistics and marketing plans.

Within the OFP, the aim of the OM activity is to receive orders from customers and to commit order requests. In other words, OM consists of analysing orders an managing backlog in order to determine if, how and when orders can be delivered. Its main objectives can be summarized into two dimensions (Lin and Shaw, 1998):

- Delivering qualified products to fulfil customer orders at the right time and right place;

- Achieving agility to handle uncertainties from internal or external environments.

In practice, there are techniques that enable the OM activity to partly achieve these goals by choosing between different alternatives. These techniques are: available-to-promise (ATP), advanced available-to- promise (AATP), capable-to-promise (CTP), and profitable-to-promise (PTP). However, in case of stock-out, they are insufficient for decision making in the face of certain variables such as: unknown availability, product substitution and specific operations. Based on this, our second problem statement is:

PS2: How can promised customer orders be fulfilled in case of stock-out?

Moreover, even though the OFP has a clear global objective to provide to the customer the right product, at the right price and at the right time, each functional entity that participates in this process tries to achieve their own individual objectives. These objectives are generally contradictory. For example, in case of stock-out:

- Distribution would want to delay and deliver at a later date and in one batch all the products of an order, in order to minimise the costs of transportation.

- Sales department would want to maximise the turnover of the current month by sending backorders separately.

- Marketing would not want to sell some products separately. For example, in the cosmetic industry, an order with a solar cream and a booklet cannot be delivered if one of the two articles is not available (because they are linked).

- Manufacturing would want to minimise the impact of the stock-out on its schedule (and probably also on its costs) by not changing the schedule in order to quickly produce the item out of stock.

- Of course, the Customer wants to be served as promised.

Our third problem statement can therefore be formulated as:

PS3: How should the contradictory objectives of the different functional entities be taken into consideration in the order management activity?

This paper suggests an approach that tackles the above three problem statements (PS1, PS2 and PS3) in the order fulfilment decision-making process. 


\section{Order Management Background}

As mentioned earlier, there are several techniques that support the OFP and more precisely the OM activity. The most commonly used is probably ATP (available-to-promise). According to APICS (2005), ATP is the uncommitted portion of a company's inventory and planned production maintained in the master schedule to support customer order promising. This promising mechanism is suitable for make-to-stock (MTS) production systems. Actually, in the MTS model, finished goods are produced according to demand forecast and put into inventory before an order is received from a customer.

In the make-to-order (MTO) strategy, to avoid "over promising" and "under promising" on job orders, delivery dates have to be set based on available capacity and material constraints. Techniques used to achieve this goal are referred to as capable-topromise (CTP), and they help to determine whether customers' requested delivery dates can be met (or at least, to determine the earliest realistic date a product can be promised).

ATP and CTP are searched along three dimensions (Kilger and Schneeweiss, 2000): time, customer and product. In case of shortage, different rules can be envisaged to manage the ATP/CTP along these three dimensions. As an example, customers' allocation might be done through: ranked based, fixed split, First-Come-First-Served or per committed (quotas).

A third technique used to determine the delivery date is profitable-to-promise (PTP). This method is used in manufacturing systems which have a big product mix and many kinds of customers (Ashfaque, 2005). In this case, individual orders are prioritised based on margins, preferred customers, preferred orders or any other criteria that affect the bottom line. A PTP analysis allows the business to find out if a particular order will be profitable to make, considering the raw material costs, process costs, inventory costs and other costs against the price the customer is willing to pay. The PTP technique works well for all industries, be it discrete, process, mill or flow manufacturing. In the case of MTS companies, PTP works on the data from distribution planning. In the case of MTO companies, PTP works on the data from production planning. In summary, profitability is the only criterion considered by the company.
Note that if no promise can be found for an order, the SC will not be able to fulfil the order within the allocation planning horizon (Kilger and Schneeweiss, 2000). But orders have to be fulfilled nevertheless! Today, no ATP method enables to manage bulk orders in order to deliver them more responsively.

Some authors have proposed to develop the advanced available-to-promise (AATP) in order to enhance the responsiveness of order promising and the reliability of order fulfilment (Pibernik, 2005). AATP directly links available resources (i.e. finished goods and work-in-progress) as well as raw materials, production and distribution capacity with customer orders in order to improve the overall performance of the SC/DC. While ATP consists of simply monitoring the uncommitted portion of current and future available finished goods, AATP provides a decision-making mechanism for allocating available finished goods inventory to customer orders and concluding order quantities and due date quotes.

The characteristics used for classifying AATP are (Pibernik, 2005):

- The availability level: finished goods inventory or supply chain resources (including raw materials, work-in-progress, finished goods...);

- The operating mode: real time or batch mode;

- The interaction with manufacturing resource planning: active (AATP modifies the Master Schedule) or passive (AATP is done independently with information regarding finished goods and resource availability).

Some additional advanced ATP functionalities are currently discussed by researchers (Kilger and Schneeweiss, 2000; Pibernik, 2005). These functionalities mainly refer to strategies applied to an anticipated shortage of finished goods or supply chain resources. Siala et al. (2006) summarise them in a fourth dimension which is the flexibility of the solution proposed to the customer. Three different strategies can be supported by AATP (Pibernik, 2005):

- AATP with substitute products: in certain cases substitute products can be delivered within the given delivery time window in place of the product originally ordered by the customer. 
- Multi-location AATP: if the customer order cannot be fulfilled with the finished goods or supply chain resources at a given location, available finished goods and resources can be sourced at other locations.

- AATP with partial delivery: if the ordered quantity is not available within the given delivery time window, the customer order can be fulfilled with two or more partial deliveries.

These different strategies can be combined in any possible sequence in the AATP planning mechanism (Pibernik, 2005). Besides generating these strategies sequentially, they can be combined in the AATP planning mechanism in such a way that all feasible solutions are determined and assessed simultaneously. This provides a partial answer to problem statement 2 , presented in section 2. But, no research work seems to have developed rules for identifying and assessing alternative strategies in case of a temporary shortage of finished goods (Pibernik, 2005).

It becomes clear that models and algorithms generating order quantity and due date quotes, based on pertinent information concerning customer orders, uncommitted finished goods quantities as well as customer priority and preference, represent the core of AATP planning mechanism (Pibernik, 2005). Though some authors such as Pibernik (2005) and Siala et al. (2006) have tried to consider these strategies in their AATP planning mechanism, none seems to have studied the impact of the different functional entities involved in the OFP (see problem statement 3, as discussed in section 2). Practically, these contributions consider a single stakeholder's point of view, that of the customer (Pibernik, 2005) or that of the Decision Centre (Siala et al., 2006)

\section{Our Proposition}

\subsection{Multi-Criteria Advanced ATP Overview}

While Siala et al. (2006) have proposed a planning mechanism for a multi-location real-time Advanced Available-to-promise (AATP) based on finished goods inventory and substitute products, we propose to analyse multi-item orders through a multi-location batch-time AATP based on finished goods inventory, substitute products and partial delivery within a non sequential mode. In other words, the aim of this research is to present a multicriteria approach to manage bulk orders by developing a specific AATP that:

- Analyses in a batch mode orders that are composed of several products;

- Studies partial deliveries, substitute products, delayed deliveries and alternative location possibilities;

- Enables to compare all the order delivery strategies by considering criteria and constraints of the different actors that are involved in the order fulfilment process (non-sequential mode), thereby integrating the overall chain from both perspectives of the OFP - supply and demand.

The mechanism developed (see Figure 1) is triggered by the arrival of a customer order. This mechanism is composed of six steps:

1. The allocation is checked. Allocations are calculated from forecasts and relate to the commitments made to the customer. If and when there is no allocation, the order should not be fulfilled. However, an order can sometimes be fulfilled if there is overstock.

2. When the line refers to a commitment, the stock quota availability for all products of the order (original products and potential substitutes) within the time window is checked on all sourcing locations (normal and alternative).

3. In the event of shortage of a product, the AATP looks for alternative strategies to serve the customer efficiently, effectively and responsively. Consequently, the customer's requirements must be known: the maximum number of shipments that can be accepted, the authorisation to split a line of the order (that is, the possibility of delivering an order line in many instalments), the maximum delay that is acceptable to the customer and the possibility of substituting some products of the order.

4. In case of stock-out, the problem boils down to fulfilling the customer order as well as possible, while taking into consideration the conflicting objectives of the different stakeholders: distribution, sales, marketing, manufacturing, and of course, the customer. This step consists therefore of defining several strategies corresponding to different order fulfilment 
Figure 1. Multi criteria Advanced ATP

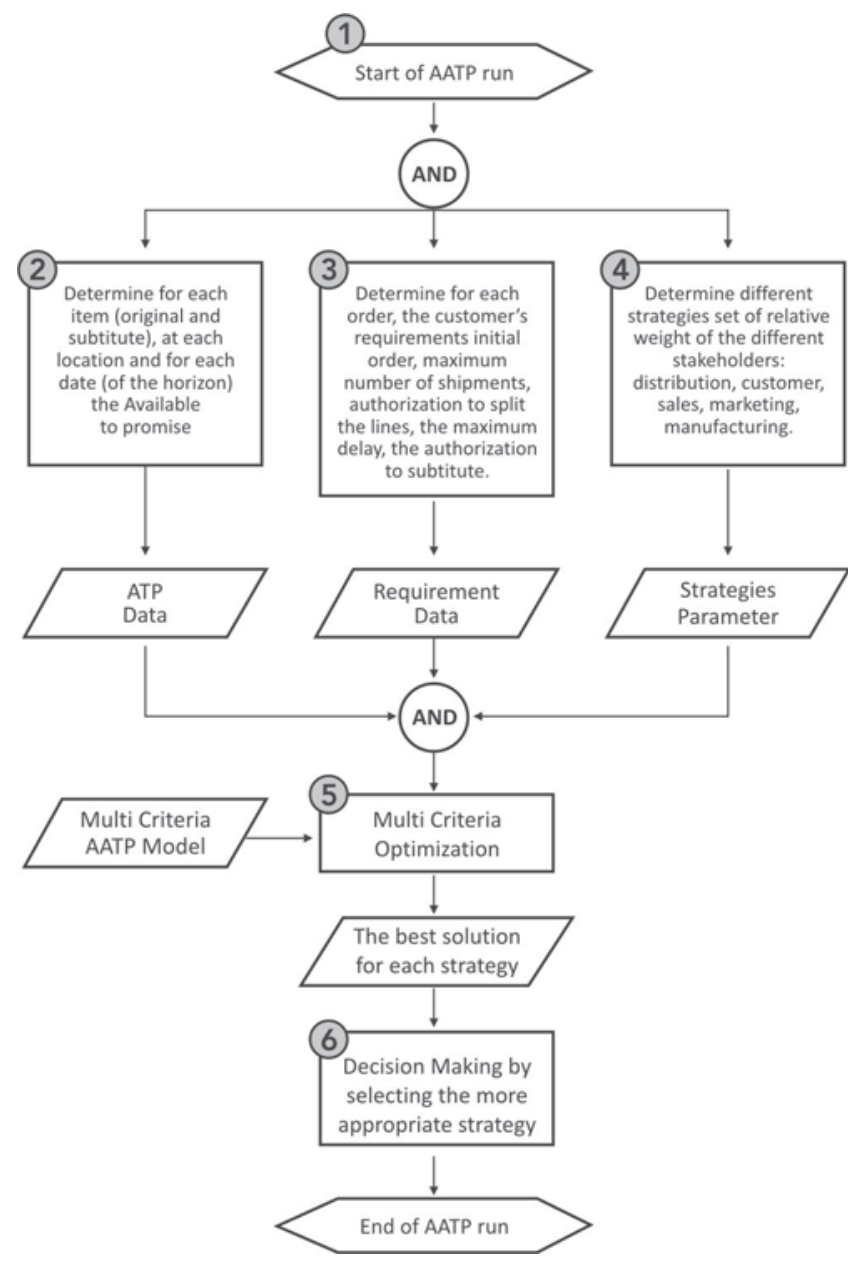

policies. For instance, if emphasis is laid on the supplier's objectives, then distribution costs (cost of order preparation and transportation) would be considered more important than the cost of delay. This step produces a set of strategies, depicted through a set of parameters (coefficients) that will permit to translate each of the policies in the AATP model. This model will be developed in the subsections hereafter.

5. By using our multi-criteria AATP model, an optimisation program is run. The aim being to reach an acceptable compromise between the expectations of the SC and those of the DC, this step establishes, for each of the strategies (defined in section 4), the best solution with respect to the objective function of the model. This function is based on a multi-criteria approach that takes into account the constraints and objectives of all the actors that are involved in the OFP.
6. This assessment then determines the list of good solutions that is used to execute the OM Activity. Depending on practical business realities, the decision maker has to choose the most efficient, effective and/or responsive solution.

\subsection{Assumption}

In this study we have considered only orders that have already been recorded in the order portfolio of the company. The OM activities have to manage only firm orders. Moreover, as for any traditional ATP the knowledge of future productions are also considered to be known, firm, and stable. Consequently, we have made the assumption of invariability in the data of our problem. Then, for this work we assume the hypothesis of a deterministic environment.

\subsection{Multi-Criteria Assessment Hypotheses}

In this section, we will describe the hypotheses of our model and the associated symbols used in it. The first hypothesis considers that an order is composed of $n$ different lines (multi-references order). Each line can be defined by a product $\mathrm{p}$, a quantity $\mathrm{D}_{\mathrm{p}}$ and a weight $\mathrm{W}_{\mathrm{p}}$. The product $\mathrm{p}$ is positioned on the line $\mathrm{p}$. The $\mathrm{g}$ index represents the weight group (bucket) of the delivery. The weight group has an inferior limit, $\mathrm{kmin}_{\mathrm{g}^{\prime}}$ and a superior limit, $\mathrm{kmax}_{\mathrm{g}}$.

The customer wants to be delivered at a Due Date, $\mathrm{DD}$. There is a delay as soon as the effective delivery date is beyond the DD. The latest delivery date authorised by the customer is referred to as the Deadline, DL. Beyond this DL, the customer will refuse the backorder. If all the ordered quantity is not delivered, there is a shortage cost, $\mathrm{CSh}_{\mathrm{p}}$.

We also consider a delay cost, $\mathrm{CDV}_{\mathrm{p}}$. This cost depends on the laps of time between DD and the effective delivery date, as well as on the quantity delivered late. There is also a delay penalty, which is considered as a fixed cost, CDF.

An order can be delivered in several instalments. Nshipmax stands for the maximum number of shipments for an order. We consider that there are two shipments as soon as an order is delivered from two different sources $s$ or prepared from a unique source but at two different dates.

One shipment from a sourcing site s implies a preparation cost $(\mathrm{CP})$ that includes a fixed part $\mathrm{CPF}_{\mathrm{s}}$ (which depends on the sourcing site) and a variable 
part $\mathrm{CPV}_{\mathrm{ps}}$ that depends also on the sourcing site, as well as on the quantity of product $\mathrm{p}$ picked.

A transportation cost is also considered. This cost is defined as a variable cost, $\mathrm{CTV}_{\mathrm{gs}}$ that depends on the weight of the quantity shipped and the distance between the sourcing site $s$ and the customer.

Given that an order line p can be delivered in

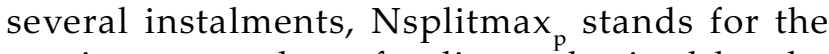
maximum number of splits authorised by the customer, for a given line. We consider that a line is split if and when the overall quantity of the line is delivered in several shipments. Two different cases must therefore be considered: the total quantity is shipped from a sole source at different dates or the total quantity is shipped from different sources. No particular cost has been associated to this in order not to penalise the supplier twice. Actually, as soon as a line is split, the whole order will be delivered late (entailing therefore a delay cost) or delivered from different sources (entailing therefore an increase in the transportation cost).

In this study, we have envisaged the possibility of using a substitute product in place of the product in shortage. Consequently, the original product $p$ can be substituted by a set of products $S_{p}$. We consider that $\mathrm{P}$ (group of demanded products) and $\mathrm{S}$ (group of substitute products) are disjoined. Then, let us consider $R_{r}$ as the set of products of $P$ that $r$ can replace.

The cost of substitution (denoted by QS $_{\mathrm{p}}$ ) depends only on the quantity of the substitute. We note that all products (original or substitute) can be delivered from different sources s.

\subsection{Multi-Criteria Assessment Model}

Here, we define the elements used in our AATP model. The model concerns the processing of a single order (and consequently of a single customer) and is based on an order fulfilment process viewed from the receiving end rather than from the shipping end. The notations used as indexes are summarised as follows:

\begin{tabular}{cl}
\hline Notations & \multicolumn{1}{c}{ Explanation } \\
\hline$p$ & Product index, $p=1 \ldots \mathrm{n}, \mathrm{n}$ is the total number of lines in the order. \\
$\mathrm{r}$ & Substitute product (replacement product) index \\
$\mathrm{s}$ & Source (distribution centre) index, $\mathrm{S}=1 \ldots \mathrm{S}, \mathrm{S}$ is the number of \\
$\mathrm{t}$ & sources \\
$\mathrm{g}$ & Time period index, $\mathrm{t}=1 \ldots \mathrm{T}, \mathrm{T}$ is the planning horizon \\
& Weight group index, $\mathrm{g}=1 \ldots \mathrm{G}, \mathrm{G}$ is the number of weight brackets \\
\hline
\end{tabular}

Using the above indexes, the parameters of our model are summarised as follows:

\begin{tabular}{|c|c|}
\hline Notations & Explanation \\
\hline$S_{p}$ & Set of substitute products for product $p$. \\
\hline$R_{r}$ & Set of products for which $r$ can be a substitute \\
\hline$D_{p}$ & Demand of product $p$ in a given order. \\
\hline$W_{p}$ & Weight attached to product $p$ \\
\hline $\mathrm{kmin}_{\mathrm{g}}$ & Inferior limit of weight group g \\
\hline $\operatorname{kmax}_{g}$ & Superior limit of weight group $g$ \\
\hline $\operatorname{ATP}_{\mathrm{pst}}$ & Quantity of product $p$ available on site s on date $t$ \\
\hline Nshipmax & Maximum number of shipments allowed \\
\hline Nsplitmax $_{p}$ & Maximum number of splits allowed for a given order line $p$ \\
\hline DD & Due Date \\
\hline $\mathrm{DL}$ & Deadline \\
\hline $\mathrm{T}$ & Planning horizon \\
\hline $\mathrm{DL}_{\mathrm{s}}$ & Delivery time from site s to customer \\
\hline $\mathrm{CPF}_{\mathrm{s}}$ & Fixed preparation cost for site s \\
\hline $\mathrm{CPV}_{\mathrm{ps}}$ & Preparation cost for product p on site s \\
\hline $\mathrm{CTV}_{\mathrm{gs}}$ & $\begin{array}{l}\text { Transportation cost for a delivery within weight group } \mathrm{g} \text {, from site } \mathrm{s} \\
\text { to customer }\end{array}$ \\
\hline CDF & $\begin{array}{l}\text { Fixed penalty if there is a delay of at least one period within the } \\
\text { order delivery time window (for } \mathrm{DD}<\mathrm{t}<\mathrm{DL} \text { ). }\end{array}$ \\
\hline $\mathrm{CDV}_{\mathrm{p}}$ & Cost of delay for one period for product $\mathrm{p}$ (for $\mathrm{DD}<\mathrm{t}<\mathrm{DL}$ ). \\
\hline $\mathrm{CSV}_{\mathrm{p}}$ & Cost of substitution for product $p$ \\
\hline $\mathrm{CSh}_{\mathrm{p}}$ & Cost of shortage for product $p$ \\
\hline
\end{tabular}

The variables of the model are summarized as follows:

\begin{tabular}{|c|c|}
\hline Notations & Explanation \\
\hline$X_{p s t}$ & $\begin{array}{l}\text { Quantity of product p picked on site s (on date } t \text { - DLs) and delivered } \\
\text { on date } t\end{array}$ \\
\hline$X C_{\text {pst }}$ & Total quantity of product $p$ picked on site $s$ and delivered on date $t$ \\
\hline$X R_{\text {rst }}$ & $\begin{array}{l}\text { Quantity of substitute product } r \text { picked on site } s \text { and delivered on } \\
\text { date } t\end{array}$ \\
\hline $\mathrm{XRC}_{\text {pst }}$ & $\begin{array}{l}\text { Total quantity of substitute product r picked on site s and delivered } \\
\text { on date } t\end{array}$ \\
\hline$Y_{\text {rpst }}\left(r S_{p}\right)$ & $\begin{array}{l}\text { Quantity of product r substituted to } p \text {, picked on site s and delivered } \\
\text { on date } t\end{array}$ \\
\hline$Q_{p t}$ & $\begin{array}{l}\text { Quantity of product delivered on date } t \text { to fill line } p \text { (product } p \text { or } \\
\text { substitute) }\end{array}$ \\
\hline $\mathrm{QS}_{\mathrm{p}}$ & Quantity of product $p$ substituted \\
\hline Shortage $_{p}$ & Final backorder quantity of product $p$ \\
\hline OD & $\begin{array}{l}\text { Boolean variable linked to the Due Date (Order Delay), } O D=1 \text { if } \\
\text { there is a delay (i.e. } D D<t<D L \text { ), } 0 \text { otherwise }\end{array}$ \\
\hline $\mathrm{DCU}_{\text {st }}$ & $\begin{array}{l}\text { Variable linked to the use of source } \mathrm{s} \text { for a delivery on date } \mathrm{t} \\
\text { (Distribution Center Using), } \mathrm{DCU}_{\mathrm{st}}=1 \text { if site } \mathrm{s} \text { is used, } 0 \text { otherwise }\end{array}$ \\
\hline $\mathrm{R}_{\mathrm{pst}}$ & $\begin{array}{l}\text { Quantity of product delivered on date } t \text { from site } s \text { to fill the line } p \\
\text { (product p or substitute) }\end{array}$ \\
\hline $\mathrm{OR}_{\mathrm{pst}}$ & $\begin{array}{l}\text { Boolean variable linked to the quantity of product delivered on date } t \\
\text { from site } s \text { to fill line } p\end{array}$ \\
\hline SUB $_{\mathrm{p}}$ & $\begin{array}{l}\text { Variable linked to substitution, } \text { SUB }_{p}=1 \text { if product } p \text { is substituted, } \\
0 \text { otherwise }\end{array}$ \\
\hline $\mathrm{DEL}_{\text {stg }}$ & $\begin{array}{l}\text { Boolean variable linked to weight group } \mathrm{g} \text { of a delivery from site } \mathrm{s} \text { on } \\
\text { date } t, D E \mathrm{~L}_{\text {stto }}=1 \text { if there is a delivery within the weight group } \mathrm{g} \text { from } \\
\text { site } \mathrm{s} \text { on date } t, 0 \text { otherwise }\end{array}$ \\
\hline
\end{tabular}


Finally, the objective function (2) tries to minimise the total cost of the system (preparation costs CP, transportation costs $\mathrm{CT}$, delay costs $\mathrm{CD}$, substitution costs CS and shortage costs CSh). We propose to balance the different costs of the system in order to be able to reflect the strategy of the network. The aim is to minimise the total cost:

Minimise $[\mathrm{w}(\mathrm{CP}) * \mathrm{CP}+\mathrm{w}(\mathrm{CT}) * \mathrm{CT}+\mathrm{w}(\mathrm{CD}) * \mathrm{CD}+$

$$
\mathrm{w}(\mathrm{CS}) * \mathrm{CS}+\mathrm{w}(\mathrm{CSh}) * \mathrm{CSh}]
$$

where $\mathrm{w}$ is the balancing coefficient for a cost.

The different costs are defined below.

Order Preparation Cost (CP):

$$
\begin{aligned}
& \mathrm{CP}=\quad\left(\sum_{t} \mathrm{DCU}_{\mathrm{st}}\right) * \mathrm{CPF}_{\mathrm{s}}+\sum_{p} \sum_{s} \\
& {\left[\sum_{t}\left(\mathrm{X}_{\mathrm{pst}}+\sum_{i \in S p} Y_{i p s t}\right)\right] * \mathrm{CPV}_{\mathrm{ps}}}
\end{aligned}
$$

Transportation Cost (CT):

$$
\mathrm{CT}=\sum_{s} \sum_{t}\left[\sum_{p}\left(\mathrm{X}_{\mathrm{pst}}+\sum_{i \in S p} Y_{i p s t}\right)^{*} \mathrm{~W}_{\mathrm{p}}\right]^{*} \mathrm{CTV}_{\mathrm{gsc}}
$$

Delay Cost (CD):

$$
\begin{aligned}
\mathrm{CD}= & \mathrm{OD} * \mathrm{CDF}+\sum_{t>D D} \sum_{p} \mathrm{Q}_{\mathrm{pt}}{ }^{*} \mathrm{CDV}_{\mathrm{p}}{ }^{*}(\mathrm{t}-\mathrm{DD}) \\
& \text { for DD t DL }
\end{aligned}
$$

Substitution Cost (CS):

$\mathrm{CS}=\sum_{p} \mathrm{QS}_{\mathrm{p}}{ }^{*} \mathrm{CSV}_{\mathrm{p}}$

Shortage Cost (CSh):

$\mathrm{CSh}=\sum_{p}$ Shortage $_{\mathrm{p}}{ }^{*} \mathrm{CSh}_{\mathrm{p}}$

In our AATP model the above objective function is solved subject to 19 constraint functions, as expressed in equations (8) to (26).
The sum of the different cost balancing coefficients must be equal to 1 :

$w(C P)+w(C T)+w(C D)+w(C S)+w(C S h)=1$

The quantity of product $p$ delivered on date $t(t<D L)$ must be equal to the total of product $p$ or substitute product $r$ delivered from all sourcing sites s:

$\mathrm{Q}_{\mathrm{pt}}=\sum_{s} X_{p s t}+\sum_{s} \sum_{r \in S p} Y_{r p s t} \quad$ for $\mathrm{t}<\mathrm{DL}$

The customer does not allow any deliveries after the date DL:

$\mathrm{Q}_{\mathrm{pt}}=0 \quad$ if $\mathrm{t}>\mathrm{DL}$

In order to be able to calculate the preparation and transportation costs, we have to determine the quantity of product $p$ arriving from each sourcing site $s$ at each date $t$ :

$\mathrm{R}_{\mathrm{pst}}=\mathrm{X}_{\mathrm{pst}}+\sum_{r \in S p} Y_{r p s t} \quad$ for $\mathrm{t}<\mathrm{DL}$

The total quantity of product $p$ delivered from a given source $s$ at date $t$ must be lower than or equal to the quantity available at this source $s$ at the shipment date $\left(t-D L_{s}\right)$ :

$\mathrm{XC}_{\mathrm{pst}}=\sum_{i=1, t} \mathrm{X}_{\mathrm{psi}}$

$\mathrm{XC}_{\mathrm{pst}} \leq \mathrm{ATP}_{\mathrm{pst}-\mathrm{DLs}} \quad$ for $\mathrm{t}>\mathrm{DL}_{\mathrm{s}}$

The quantity of product $p$ delivered from a given source $s$ at a given date $t$ is equal to 0 if the date $t$ is lower than or equal to the delivery time from the site $s$ :

$X_{p s t}=0 \quad$ for $\mathrm{t} \leq \mathrm{DL}_{\mathrm{s}}$

There are similar constraints for substitute products:

$\mathrm{XR}_{\mathrm{rst}}=\sum_{i \in R r} Y_{i p s t}$ 
$\mathrm{XRC}_{\mathrm{rst}}=\sum_{i=1, t} \mathrm{XR}_{\mathrm{rsi}}$

$\mathrm{XRC}_{\mathrm{rst}} \leq \mathrm{ATP}_{\mathrm{rst}-\mathrm{DLs}} \quad$ for $\mathrm{t}>\mathrm{DL}_{\mathrm{s}}$

$$
\mathrm{XR}_{\mathrm{rst}}=0 \quad \text { for } \mathrm{t} \leq \mathrm{DL}_{\mathrm{s}}
$$

Within the whole time window, the quantity of product $p$ substituted is equal to the sum of the quantity of product $r$ substituted to $p$ :

$\mathrm{QS}_{\mathrm{p}}=\sum_{r \in S p} \sum_{s} \sum_{t} \mathrm{Y}_{\mathrm{rpst}}$

The shortage is equal to the total quantity ordered minus the total quantity delivered at date $D L$ :

$\mathrm{QP}_{\mathrm{pDL}}+$ Shortage $_{\mathrm{p}}=\mathrm{D}_{\mathrm{p}}, \forall \mathrm{p}$

For a given order, a sourcing site must be used less than the maximum number of shipments acceptable for the order:

Nshipmax $\geq \sum_{s} \sum_{t} \mathrm{DCU}_{\mathrm{st}}$

Each time a sourcing site is used $\left(\mathrm{DCU}_{\mathrm{st}}=1\right)$, the quantity of product delivered is limited by the total demand of $p$ (for each product and each distribution centre). Thus if $\mathrm{DCU}_{\mathrm{s}}=0$ (an unused source $s$ ), then $\mathrm{Q}_{\mathrm{pt}}=0$.

$$
\sum_{p} X_{p s t}+\sum_{p} \sum_{i \in S p} Y_{i p s t} \leq \sum_{p} D_{p} * \mathrm{DCU}_{\mathrm{st}}
$$

The number of pickings to fill a given order line $p$ is limited by the maximum number of splits acceptable by the customer. Because 1 split implies 2 shipments, we have to consider

$\mathrm{OR}_{\mathrm{pst}}-1$ :

$\operatorname{Nsplitmax}_{\mathrm{p}} \geq \sum_{s} \sum_{t} \mathrm{OR}_{\mathrm{pst}}-1$
For each substitution $\left(\mathrm{SUB}_{\mathrm{p}}=1\right)$, the quantity of substituted product $p$ delivered must be inferior to the total demand of $p$ (valid for each product). If $\mathrm{SUB}_{\mathrm{p}}=0$, then $\mathrm{QS}_{\mathrm{p}}=0$.

$\mathrm{QS}_{\mathrm{p}} \leq \mathrm{D}_{\mathrm{p}} * \mathrm{SUB}_{\mathrm{p}}$

A delivery must be done in only one weight group.

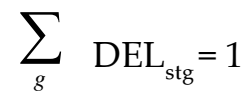

The weight of the delivery must fall between the limits of the weight group.

$\operatorname{kmin}_{\mathrm{g}}{ }^{*} \mathrm{DEL}_{\mathrm{stg}}<\sum_{p}\left(\left(\mathrm{X}_{\mathrm{pst}}+\sum_{i \in S p} Y_{i p s t}\right) * \mathrm{~W}_{\mathrm{p}}\right)<\operatorname{kmax}_{\mathrm{g}}$

${ }^{*} \mathrm{DEL}_{\mathrm{stg}}$

\section{Numerical Experiment}

\subsection{Method}

In this section, a numerical example is used to test our model. The supply network including substitution of products and two sourcing site. Due to the restrictive length of this paper, we present here the analysis of only three significant strategies regarding to the concepts of leagility: efficient delivery, responsive delivery and leagile delivery.

In our model, we have considered the OFP as being composed of the following elements: order preparation, transportation, substitution, delay, shortage (undelivered quantity). With respect to these elements, the delivery strategies can be implemented in the following way:

- Efficient delivery strategy: a similar weight should be put on all the costs elements in the objective function stated in equation 2 . In other words, all the coefficients have to be equal so that the optimum solution would be found with respect to the total cost.

- Flexible delivery strategy: a higher weight should be put on shortage, the objective being to minimise shortage. In a way, the flexibility of the network allows to maximise the effectiveness of the delivery by ensuring a 100\% 
of completeness (all demanded products are delivered even with a delay).

- Responsive delivery strategy: a higher weight is put on delay, the objective being to deliver as quickly as possible (maximum of products in a minimum of time).

Each strategy is implemented using a set of values relative to the five cost balancing coefficients $-\mathrm{w}(\mathrm{CP}), \mathrm{w}(\mathrm{CT}), \mathrm{w}(\mathrm{CD}), \mathrm{w}(\mathrm{CS})$ and $\mathrm{w}(\mathrm{CSh}) . \mathrm{A} 0.1$ indentation is used to set these coefficients.

\subsection{Data}

We consider an order placed by a customer at $t=0$. This order is composed of three different products $\mathrm{M}, \mathrm{N}$ and $\mathrm{O}-$ and the demand is 100 units for each. The due date is week 1 . But in week 1 , there is a shortage of all these products. The customer does not want to receive his order in more than three instalments and the order line of product $\mathrm{M}$ cannot be split more than once. The latest delivery date acceptable by the customer is week 5 . The unit selling prices of the different products are $\$ 100$ for product M, $\$ 160$ for product $\mathrm{N}$ and $\$ 100$ for product $\mathrm{O}$. Regarding the experiment, products MS and NS are considered as substitutes for products $\mathrm{M}$ and $\mathrm{N}$ respectively. Two sourcing plan S1 and S2 are opened and some inventories (for all the products) are introduced. The set of data used to perform this experiment is shown in Table 1.

Table 1. Data for experiment

\begin{tabular}{|c|c|c|c|c|c|}
\cline { 2 - 6 } \multicolumn{1}{c|}{} & \multicolumn{5}{c|}{ Items from soure S1 } \\
\hline Period & $\mathbf{M}$ & $\mathbf{N}$ & $\mathbf{O}$ & $\mathbf{M S}$ & $\mathbf{N S}$ \\
\hline $\mathbf{1}$ & 50 & 30 & 20 & 0 & 10 \\
\hline $\mathbf{2}$ & 50 & 100 & 20 & 0 & 10 \\
\hline $\mathbf{3}$ & 50 & 100 & 90 & 0 & 10 \\
\hline $\mathbf{4}$ & 90 & 100 & 100 & 0 & 10 \\
\hline $\mathbf{5}$ & 100 & 100 & 100 & 0 & 10 \\
\hline Cost & & & & & \\
\hline CPVsp & 3 & 4,5 & 3 & 4 & 5,5 \\
\hline CPFs & 200 & 200 & 200 & 200 & 200 \\
\hline CDF & 10 & 10 & 10 & 10 & 10 \\
\hline CDVp & 25 & 40 & 25 & 25 & 40 \\
\hline CPEVp & 200 & 360 & 200 & & \\
\hline & & & & & \\
\hline Weight & 1 & 0,7 & 0,5 & 1 & 0,7 \\
\hline
\end{tabular}

Concerning the transportation cost, three weight groups are defined for a shipment: from $0-$ $50 \mathrm{~kg}, 50-200 \mathrm{~kg}$, and above $200 \mathrm{~kg}$. For these groups, the corresponding transportation costs per kilogram are respectively:

- $\$ 10, \$ 8$ and $\$ 5$, from sourcing site 1 to the customer;

- $\$ 12, \$ 10$ and $\$ 7$, from sourcing site 2 to the customer.

We assume that all products shipped in a given week are delivered the same week. The transportation time ( 24 hours in our case example) is therefore negligible and is not taken into consideration.

\subsection{Results}

As discussed previously, the efficient delivery strategy is based on the minimisation of the total cost. Consequently, the same value of 0.2 is assigned to the four coefficients: $\mathrm{w}(\mathrm{CP}), \mathrm{w}(\mathrm{CT}), \mathrm{w}(\mathrm{CD}), \mathrm{w}(\mathrm{CS})$ and $\mathrm{w}(\mathrm{CSh})$. The solution obtained turns out to be the most economic, with a total cost of \$12 424 (see Table 2).

The flexible delivery strategy aims to maximise the completeness percentage of the delivery. In other words, the aim of this strategy is to avoid shortage, at the expense of a high total cost and a low responsiveness. Consequently, the coefficient $\mathrm{w}(\mathrm{CSh})$ is assigned a value of 0.1 whereas the coefficients $\mathrm{w}(\mathrm{CP}), \mathrm{w}(\mathrm{CS}), \mathrm{w}(\mathrm{CT})$ and $\mathrm{w}(\mathrm{CD})$ are

\begin{tabular}{|c|c|c|c|c|c|}
\cline { 2 - 6 } \multicolumn{1}{c|}{} & \multicolumn{5}{c|}{ Items from source S2 } \\
\hline Period & $\mathbf{M}$ & $\mathbf{N}$ & $\mathbf{O}$ & $\mathbf{M S}$ & $\mathbf{N S}$ \\
\hline $\mathbf{1}$ & 20 & 40 & 0 & 10 & 30 \\
\hline $\mathbf{2}$ & 30 & 40 & 50 & 10 & 30 \\
\hline $\mathbf{3}$ & 50 & 60 & 50 & 10 & 30 \\
\hline $\mathbf{4}$ & 50 & 60 & 50 & 10 & 30 \\
\hline $\mathbf{5}$ & 50 & 60 & 50 & 10 & 30 \\
\hline Cost & & & & & \\
\hline CPVsp & 4 & 5,5 & 4 & 5 & 6,5 \\
\hline CPFs & 200 & 200 & 200 & 200 & 200 \\
\hline CDF & 10 & 10 & 10 & 10 & 10 \\
\hline CDVp & 25 & 40 & 25 & 25 & 40 \\
\hline CPEVp & 200 & 360 & 200 & & \\
\hline & & & & & \\
\hline Weight & 1 & 0,7 & 0,5 & 1 & 0,7 \\
\hline
\end{tabular}


Table 2. Results for efficient delivery strategy

\begin{tabular}{|c|c|c|c|c|c|c|c|c|c|c|}
\hline \multicolumn{6}{|c|}{ Delivery Plan } & \multicolumn{5}{|c|}{ Parameters } \\
\hline Site1 & $\mathbf{M}$ & $\mathbf{N}$ & \multicolumn{3}{|c|}{\begin{tabular}{l|l|l|} 
O & MS & NS \\
\end{tabular}} & $\mathbf{w}(\mathbf{C T})$ & $\mathbf{w}(\mathbf{C P})$ & $\mathbf{w}(\mathbf{C S})$ & $\mathbf{w}(\mathbf{C D})$ & $\mathbf{w}(\mathbf{P e})$ \\
\hline Week 1 & 50 & 30 & 20 & & & 0.2 & 0.2 & 0.2 & 0.2 & 0.2 \\
\hline \multicolumn{6}{|l|}{ Week 2} & \multicolumn{5}{|c|}{ Performance Criteria } \\
\hline Week 3 & & & 30 & & & \multicolumn{2}{|c|}{ Cost } & Weeks & \multicolumn{2}{|c|}{ \% Completeness } \\
\hline \multicolumn{6}{|l|}{ Week 4} & \multicolumn{2}{|c|}{$\$ 12424$} & 3 & \multicolumn{2}{|c|}{$96 \%$} \\
\hline \multicolumn{6}{|l|}{ Week 5} & & & & & \\
\hline \multicolumn{6}{|c|}{ Delivery Plan } & & & & & \\
\hline Site 2 & $\mathbf{M}$ & $\mathbf{N}$ & $\mathbf{O} 1$ & MS & NS & & & & & \\
\hline \multicolumn{6}{|l|}{ Week 1} & & & & & \\
\hline Week 2 & 30 & 40 & 50 & 10 & 20 & & & & & \\
\hline \multicolumn{6}{|l|}{ Week 3} & & & & & \\
\hline \multicolumn{6}{|l|}{ Week 4} & & & & & \\
\hline Week 5 & & & & & & & & & & \\
\hline \multicolumn{11}{|c|}{ ery Strategy 1 : Efficient } \\
\hline
\end{tabular}

Table 3. Results for flexible delivery strategy

\begin{tabular}{|c|c|c|c|c|c|c|c|c|c|}
\hline \multicolumn{5}{|c|}{ Delivery Plan } & \multicolumn{5}{|c|}{ Parameters } \\
\hline Site1 & $\mathbf{M}$ & $\mathbf{N}$ & $\mathbf{O}$ & \begin{tabular}{l|l} 
MS & NS \\
\end{tabular} & $\mathbf{w}(\mathbf{C T})$ & $\mathbf{w}(\mathbf{C P})$ & $\mathbf{w}(\mathbf{C S})$ & $\mathbf{w}(\mathbf{C D})$ & $\mathbf{w}(\mathbf{P e})$ \\
\hline Week 1 & 50 & 30 & 20 & 10 & 0.1 & 0.1 & 0.1 & 0.1 & 0.6 \\
\hline Week 2 & & & & & \multicolumn{5}{|c|}{ Performance Criteria } \\
\hline Week 3 & & 60 & 70 & & \multicolumn{2}{|c|}{ Cost } & Weeks & \multicolumn{2}{|c|}{ \% Completeness } \\
\hline Week 4 & & & & & \multicolumn{2}{|c|}{$\$ 15010$} & 3 & \multicolumn{2}{|c|}{$100 \%$} \\
\hline Week 5 & & & & & & & & & \\
\hline \multicolumn{5}{|c|}{ Delivery Plan } & & & & & \\
\hline Site 2 & $\mathbf{M}$ & $\mathbf{N}$ & $\mathbf{O}$ & MS $\mathbf{N S}$ & & & & & \\
\hline Week 1 & & & & & & & & & \\
\hline Week 2 & & & & & & & & & \\
\hline Week 3 & 50 & & 10 & & & & & & \\
\hline Week 4 & & & & & & & & & \\
\hline Week 5 & & & & & & & & & \\
\hline & & & & & \multicolumn{5}{|c|}{ Delivery Strategy 2 : Flexible } \\
\hline
\end{tabular}

assigned a value of 0.1 . This strategy gives a delivery plan that enables to deliver all the products but with a higher total cost than in the efficiency strategy (see Table 3).
The responsive delivery strategy implies quickness and aims to deliver a maximum of the ordered quantity as soon as the products are available. In other words, this strategy tries to 
Table 4. Results for responsive delivery strategy

\begin{tabular}{|c|c|c|c|c|c|c|c|c|c|c|}
\hline \multicolumn{6}{|c|}{ Delivery Plan } & \multicolumn{5}{|c|}{ Parameters } \\
\hline Site1 & $\mathbf{M}$ & $\mathbf{N}$ & $\mathbf{O}$ & \multicolumn{2}{|c|}{ MS NS } & $\mathbf{w}(\mathbf{C T})$ & $\mathbf{w}(\mathbf{C P})$ & $\mathbf{w}(\mathbf{C S})$ & $\mathbf{w}(\mathbf{C D})$ & $\mathbf{w}(\mathbf{P e})$ \\
\hline Week 1 & 50 & 30 & 20 & & 10 & 0.1 & 0.1 & 0.1 & 0.6 & 0.1 \\
\hline Week 2 & & & & & & \multicolumn{5}{|c|}{ Performance Criteria } \\
\hline Week 3 & & & & & & \multicolumn{2}{|c|}{ Cost } & Weeks & \multicolumn{2}{|c|}{ \% Completeness } \\
\hline Week 4 & & & & & & \multicolumn{2}{|c|}{$\$ 15144$} & 2 & \multicolumn{2}{|c|}{$80 \%$} \\
\hline \multicolumn{6}{|l|}{ Week 5} & & & & & \\
\hline \multicolumn{6}{|c|}{ Delivery Plan } & & & & & \\
\hline$\overline{\text { Site } 2}$ & $\mathbf{M}$ & $\mathbf{N}$ & $\mathbf{O}$ & MS & & & & & & \\
\hline Week 1 & 20 & 40 & & 10 & 20 & & & & & \\
\hline Week 2 & & & 50 & & & & & & & \\
\hline Week 3 & & & & & & & & & & \\
\hline Week 4 & & & & & & & & & & \\
\hline Week 5 & & & & & & & & & & \\
\hline & & & & & & \multicolumn{5}{|c|}{ Delivery Strategy 3 : Responsive } \\
\hline
\end{tabular}

minimise delays in the delivery plan by penalising the costs of delay. Therefore, a value of 0.6 is assigned to the coefficient $\mathrm{w}(\mathrm{CD})$ and, 0.1 to $\mathrm{w}(\mathrm{CP})$ and $\mathrm{w}(\mathrm{CT})$. This set of coefficients enables to obtain the solution with the best reactivity. Actually, $80 \%$ of the customer's order has been delivered in only two weeks (see Table 4).

\subsection{Discussion}

Logically, the most efficient solution (minimal cost) is obtained within strategy 1 . However, the customer will receive his order in three times and 10 units of $\mathrm{M}$ and 10 units of $\mathrm{N}$ will be missing. The second strategy uses all the flexibility of the network (substitution and multi-sourcing) to fulfil the order. In this strategy, we wanted to support the DC point of view by guaranteeing an effective fulfilment of the order. Although the delay cost is very high, the customer will receive the totality of his order in 5 weeks. The last solution is the most responsive but the least complete and economic. This corresponds to our wish to give preference, in this case, to the reactivity of the fulfilment. The customer will not be penalized in terms of deadline (delay cost is lower than in the two other cases). But the total cost is high because there is a lack of 20 units of $\mathrm{M}$ and 30 units of $\mathrm{O}$ !
This experiment shows how orders can be analysed within a leagile step. Actually, the strategies depend on the degree of efficiency, flexibility and/or responsiveness desired by the $\mathrm{OM}$ decision makers (function of the importance of the customer, the product ordered or the SC's profitability). Therefore, the model clearly allows to support a leagile management of the orders.

\section{Conclusion and Perspectives}

Usually, when there is a shortage, OM decision makers have problems in determining satisfactory solutions to deliver orders given the disparate objectives of the different stakeholders of the value chain. Our work aims to help them by providing an ATTP decision support system. Compared to traditional AATP mechanisms, our proposition enables to clearly strike a balance between the SC and DC points of view in order to make a "leagile" decision. With the traditional sequencing AATP, OM decision makers execute the first solution that is feasible (according to the pre-determined sequence). This solution represents one, and only one, of the governance policies. Other solutions could exist and should have been studied. Our model enables to design for leagile strategies of governance 
(efficiency, responsiveness and flexibility), thereby offering different solutions. Each strategy corresponds to a particular balance of the conflicting objectives of the value chain. All the solutions can therefore be compared in order to select the most effective with regards to operational constraints.

Five main perspectives arise from this study:

- The choice of the coefficients w constitutes the set up of the different strategies. As an evidence some practical insights have to be determined in order to help managers to adjust the model to their own strategies. This work has been identified as a priority for the authors and is currently in progress.

- Given that performance criteria (flexibility, efficiency and responsiveness) are taken into account, other intermediate strategies are obtainable if we look at all the possible combinations of the criteria, including considering them individually. In this paper, we studied only three of them (considered to be the most significant and representative). Other strategies will therefore be explored in our further research by designing a complete and continuous experimental plan.

- Given the high number of variables, data and parameters included in our model, a sensitivity analysis needs to be performed in order to check whether a little change in any of these variables, data or parameters will have an impact on the outcome (strategy). For example, it would be interesting to study the impact of higher delivery lead times on the various strategies.

- As a first attempt, we designed our model and carried out experiments on only a single customer order. In the next phase, we intend to increase the scope of our model by considering a full order portfolio, which includes many customer orders.

- Finally, more value can be added by testing our model on a real business case. In this regards, we have currently an on-going company project that will enable us to test the model using the data from a European pharmaceutical firm.

\section{Abbreviations}

\begin{tabular}{ll}
\hline Abbreviation & \multicolumn{1}{c}{ Signification } \\
\hline AATP & Advanced Available-To-Promise \\
ATP & Available-To-Promise \\
CODP & Customer Order Decoupling Point \\
CTP & Capable-To-Promise \\
DC & Demand Chain \\
DCM & Demand Chain Management \\
MTO & Make-To-Order \\
MTS & Make-To-Stock \\
OFP & Order Fulfillment Process \\
OM & Order Management \\
PS & Problem Statement \\
PTP & Profitable-To-Promise \\
SC & Supply Chain \\
SCM & Supply Chain Management \\
\hline
\end{tabular}

\section{References}

APICS, (2005). American Production and Inventory Control Society Dictionary, 11th Ed., Alexandria.

Ashfaque, A. (2005). Profitable-to-promise: a new exciting era. www.technology-evaluation.com, Nov. 24.

Chang, Y., Makatsoris, H. \& Richards, H. (2003). A system enabling integrated demand/supply sides chains. The proceedings of the 9th International Conference of Concurrent Enterprising, Espoo, Finland, June.

Childerhouse, P. \& Towill, D. R. (2000). Engineering supply chains to match customer requirements. Logistics Information Management, 13(6), pp. 337-345.

Christopher, M. (1992), Logistics and Supply Chain Management, London: Pitman Publishing.

Christopher, M. \& Towill, D. R. (2000). Supply chain migration from lean and functional to agile and customised. Supply Chain Management: An International Journal, 5(4), pp. 206-213.

Croxton, K. L. (2003). The order fulfilment process. The International Journal of Logistics Management, 14(1), pp. 19-32.

Croxton, K. L., Garcia-Dastugue, S. J., Lambert, D. M. \& Rogers, D. S. (2001). The supply chain management processes. The International Journal of Logistics Management, 12(2), pp. 13-36.

Giesberts, P. M. J. \& van den Tang, L. (1992). Dynamics of the customer order decoupling point: impact on information systems for production control. Production Planning Control, 3, pp. 300-313.

Hoover, W., Eloranta, E., Holmström, J. \& Huttunen, K. (2001), Managing the demand-supply chain, New York, NY: Wiley. In Jacobs, D. (2006). 
Johansson, H. J., McHugh, P., Pendlebury, A. J. \& Wheeler, W. A. (1993), Business Process Reengineering: Breaking Strategies for Market Dominance, Chichester: John Wiley \& Sons.

Kilger, C. \& Schneeweiss, L. 2000. “Demand fulfilment and ATP" in: Stadtler and Kilger (editors), (2000), Supply chain management and advanced planning: concepts, models, software and case studies, Berlin: Springer.

Lin, F. R. \& Shaw, M. J. (1998). Reengineering the Order Fulfilment Process in Supply Chain Networks. The International Journal of Flexible Manufacturing System, 10, pp. 197-229.

Naylor, J. B., Naim, M. M. \& Berry, D. (1999). Leagility: interfacing the lean and agile manufacturing paradigm in the total supply chain. International Journal of Production Economics, 62, pp. 107-118.
Pibernik, R. (2005). Advanced available to promise: classification, selected methods and requirements for operations and inventory management. International Journal of Production Economics, 93-94, pp. 239-252.

Rainbird, M. (2004). Demand and supply chains: the value catalyst. International Journal of Physical Distribution and Logistics Management, 34(3-4), pp. 230-250.

Siala, M., Campagne, J. P. \& Ghedira, K. (2006). Proposition d'une nouvelle approche pour la gestion du disponible dans les chaînes logistiques. MOSIM'06, Rabat, Maroc, Avril.

Walters, D. (2006). Effectiveness and efficiency: the role of supply chains management. The International Journal of Logistics Management, 17(1), pp. 75-94.

Walters, D. \& Rainbird M. (2004). The demand chain as an integral component of the value chain. Journal of Consumer Marketing, 21(7), pp. 465-475

Uche OKONGWU is a Professor of Supply Chain Management (SCM) at Toulouse Business School, France. He holds an MSc degree in Mechanical Engineering and a PhD in Industrial Management. At Toulouse Business School, he has held many faculty positions such as Director of an MBA program in Aerospace Management and Director of a graduate program in SCM. His current research interest focuses on development and performance measurement of SCM systems. He is also an independent consultant on SCM issues and industrial organisation.

Matthieu LAURAS was Supply Chain Project Manager in a pharmaceutical company from 2001 to 2005. After this experience, he started an academic career. He joined the Industrial Engineering Department of the Ecole des Mines d'Albi-Carmaux (Toulouse University) as an Assistant Professor. His works mostly focus on performance and integration management of supply chain processes. His researches concern as well the industrial sector as the humanitarian sector. He has published several papers in journals and international conferences in the area of supply chain management.

Vérane HUMEZ is a PhD Student at the Industrial Engineering Department of the Ecole des Mines d'AlbiCarmaux (Toulouse University). Her research concerns the customer-driven supply chains and particularly the integration of demand chain and supply chain points of view. Her works are implemented on a real pharmaceutical supply chain.

Lionel DUPONT is a full Professor in production and operation management. He is the Director of the Industrial Engineering Department of the Ecole des Mines d'Albi-Carmaux (Toulouse University). His academic research area covers manufacturing system configuration, design, planning and scheduling and Supply Chain Management. He also worked on a variety of industrial domains (automotive, computer, pharmaceutical), published a book on industrial engineering and various articles of practical applications for industrial practioner. 